\title{
Laws and Powers in the Frame of Nature
}

\author{
Stathis Psillos ${ }^{1}$
}

Till a philosopher, at last, arose, who seems, from the happiest reasoning, to have also determined the laws and forces, by which the revolutions of the planets are governed and directed.

David Hume (First Enquiry, section I, 14)

\section{Introduction}

Within the Aristotelian framework of natural philosophy, which was dominant until the emergence of the mechanical philosophy, activity, motion and change in nature were taken to be grounded in powerful substances. From the seventeenth century on, this view started to recede in favour of a conception of nature as governed by general laws of nature and of motion in particular. This new conception was introduced, almost single-handedly, by Rene Descartes but it spread quickly. ${ }^{2}$ Part of the motivation was a thorough critique of the widespread view that, when it comes to natural bodies, they possess active and passive powers in virtue of which they interact with each other. Natural powers were taken to be necessity-enforcers in that they were, in and of themselves, principles of necessitation: given the power of X to $\Phi, \mathrm{X}$ must $\Phi$ when the appropriate circumstances arise. Hence, powers were regularity-enforcers: they accounted for the regularity there is in the world.

The new conception of laws emerged as an alternative to powers. Corporeal substances were widely taken to be passive and inert. Hence, activity, motion and change could not arise from within a powerful matter. They had to be imposed on matter from without and this meant that there was need for new principles of connection, viz., principles which determined the ways pieces of matter move and collide with each other. Laws of nature were broadly taken to be the required principles of connection. This very move was itself based on a thorough reconceptualisation of the very idea of natural law. The notion was widely applicable to rational beings only, since the dominant thought was that only rational beings can obey the law. After Descartes, the concept of law was widely taken to apply to all beings; and in particular to passive corporeal substances. $^{3}$

The new principles of connection-laws of nature-retained a key feature of the powers-based account of activity in nature, viz., necessity. They were meant to hold by necessity, thought what kind of necessity this is was very much in dispute. They were also meant to necessitate the behaviour of things: things had

\footnotetext{
${ }^{1}$ Dept of Philosophy and History of Science, University of Athens, Greece; and Rotman Institute of Philosophy, University of Western Ontario, Canada. psillos@phs.uoa.gr

2 There is important historical work concerning the origins of the concept of law of nature. For a thorough discussion and support of the claim that Descartes should be credited with initiating the modern conception, see Henry (2004).

${ }^{3}$ Hobbes resisted this trend and refrained from extending natural laws to non-rational beings. For more on this see Goudarouli \& Psillos (forthcoming).
} 
to obey the laws that governed their behaviour. But if there is no power in matter, how does matter act on matter? Broadly speaking, there are two options available, given the passivity of matter. The first is that matter exists but God is the only motive force (this is the line followed by Malebranche and came to be known as Occasionalism). The other is to deny the existence of matter altogether (since there is nothing for it to do) and to claim that God is the direct cause of all ideas in minds (this leads to Berkeley's idealism). On both options, laws play a key role: they replace powers and provide the missing connections between distinct existences.

The aim of this paper is to revisit the major arguments of the seventeenth century debate concerning laws and powers. Its primary points are two. First, though the dominant conception of nature was such that there was no room for power in bodies, the very idea that laws govern the behaviour of (bits of) matter in motion brought with it the following issue, which came under sharp focus in the work of Leibniz: how possibly can passive matter, devoid of power, obey laws? Though Leibniz's answer was to re-introduce powers, two radically different conceptualisations of the relation between laws and powers became available after him. Hume denied powers altogether, whereas Newton thought that to introduce a power is to introduce a law. The second main point will be that though laws were meant to replace powers, the real dilemma ended up being not laws vs powers, but rather necessity vs non-necessity in nature. To exploit, an expression used by Newton, the question was: what is the place of necessity in the frame of nature?

\section{Against Laws; Against Powers}

For Mediaeval thinkers, natural agency was fundamental and explicable in terms of the powers of the natural agents themselves. God, however, was taken to be the author of the order of the world and its ordering to an end. So, though there is order in the world and in this sense God is the Divine order-maker, He does not posit laws of nature over and above the active natures of natural things. Insofar as there is talk of 'laws of nature', this is a metaphorical extension of the concept from the realm of free agents to nature. ${ }^{4}$

One can see this kind of approach very clearly in the work of the late Medieval thinker Francisco Suarez. According to Thomas Aquinas (Summa, I-II q.90 art.1): "Law (lex) is a certain rule and measure in accordance with which one is induced to act or is restrained from acting" (Suarez 1612, 7) Thus put, Suarez notes, the definition of law is "too broad and general" precisely because it allows that it is applicable to non-sentient beings, since "everything has its own rule and measure, in accordance with which it operates and is induced to act or in restrained therefrom". For Suarez, however, laws, strictly speaking, require rational agency. A law is something that has to be (and can be) obeyed (executed) and this can only be satisfied by rational creatures. In this sense, the claim that non-sentient beings obey laws would amount to the claim that they act according to the their natural powers. Indeed, insofar as this metaphorical sense of law is used, it can only refer to the orderly action of natural bodies "in accordance with the inclinations imparted to them by the Author of Nature" $(1944,22)$. Seen that way, talk of natural laws is talk about natural powers. It

\footnotetext{
${ }^{4}$ This point has been recently stressed by Marilyn McCord Adams (2013).
} 
captures the natural necessity there is in nature and it is to this natural necessity that can be "metaphorically given the name of law" (ibid.).

Note, in addition, that if talk of laws of nature is talk about powers, there are as many 'laws of nature' as there are powers-a law for each power in nature. Laws of nature, then, play no role whatsoever as unifiers. Still, if this metaphorical use is made, there must be a law-maker who governs the things that 'obey the law'. As Suarez put it, insofar as non-rational beings are said to obey a law, they are "in need of a superior governing mind" (...) "and thus from every standpoint, law must be related to mind". In sum, then, talk of laws is metaphorical and its proper content concerns natural necessities which are grounded in the natural inclinations of things imparted on them by the lawmaker.

The emergence of mechanical natural philosophy in the seventeenth century brought with it a war against (natural) powers. Qua a sui generis category that explains or grounds motion and change in nature, power came under heavy fire. Here are the main arguments against powers. ${ }^{5}$

The connection problem: how are powers connected? How is it that $\mathrm{X}$ having the power to $\Phi$ and Y having the power to be $\Phi$-ed (two distinct existences) interact to give rise to an effect? According to Descartes, the power of X to $\Phi$ is not sui generis but should be understood in terms of matter in motion. All there is to explain how $\mathrm{X}$ acts on $\mathrm{Y}$ is action by contact of the parts of $\mathrm{X}$ on the parts of $\mathrm{Y}$. In his Le Monde, Descartes objected to the medieval Aristotelian view that fire has the (sui generis) power to burn wood that all there is to the action of fire on wood can and should be understood in terms of the violent and incessant motion of the parts of fire:

\begin{abstract}
When [fire] burns wood or other similar material we can see with our eyes that it moves the small parts of the wood, separating them from one another, thereby transforming the finer parts into fire, air, and smoke, and leaving the larger parts as ashes. Someone else may if he wishes imagine the 'form' of fire, the 'quality' of heat, and the 'action' of burning to be very different things in the wood. For my own part, I am afraid of going astray if I suppose there to be in the wood anything more than what I see must necessarily be there, so I am satisfied to confine myself to conceiving the motion of its parts. For you may posit 'fire' and 'heat' in the wood, and make it burn as much as you please: but if you do not suppose in addition that some of its parts move about and detach themselves from their neighbours, I cannot imagine it undergoing any alteration or change $(1998,6)$.
\end{abstract}

In effect, Descartes's point is that even if powers were posited, they would fail to explain, in and of themselves, change in nature; the proper explanation would require reference to the action of the parts of the bodies that bear the 'active power' on the parts of the bodies that bear the 'passive power'. But this very move would make powers redundant, since all the action would be due to the motion of the parts of bodies.

This kind of argument against powers is directed primarily against viewing powers as sui generis. Power is not a specific kind of cause of motion/change, distinct for each kind of motion/change. All motion/change in nature should be understood as being of the same kind, viz., the result of action by contact between the parts of matter. Objecting to the view that powers are sui generis

\footnotetext{
${ }^{5}$ For further insightful discussion, see Ott (2009, chapter 5).
} 
principles of motion, Descartes noted: "The Philosophers also posit many motions which they believe can occur without any body's changing place, such as those they call motus ad formam, motus ad calorem, motus ad quantitatem (motion with respect to form, motion with respect to heat, motion with respect to quantity) and countless others" $(1998,26)$. But he added: "I know of no motion other than that which is easier to conceive of than the lines of geometers, by which bodies pass from one place to another and successively occupy all the spaces in between" $(1998,27)$. Hence, all motion should be understood univocally as local motion, and if a sense of power is still operative it can at best be seen as the power of matter to be moved (mobility).

For Descartes, then, there are no sui-generis powers in nature. To understand all change in nature it is enough to conceive the motions of the parts of mattersubject to universal laws, as we shall see in the next section. Speaking again against the alleged sui generis power of fire to burn, Descartes $(1998,8)$ noted:

Once we appreciate that the parts of the flame move in this way, and that to understand how the flame has the power to consume the wood and to burn it, it is enough to conceive of their motions, I ask you to consider whether this is not also sufficient for us to understand how the flame provides us with heat and light. For if this is the case, the flame will need possess no other quality, and we shall be able to say that it is this motion alone that is called now 'heat' and now 'light', according to the different effects it produces.

The occultness problem: This is a version of the connection problem above. But it is worth treating it separately because the emphasis is shifted to the claim that, in principle, there is no understanding of how a power brings about its effect. In a letter to Regius in January 1642, Descartes (1991, 208-9) noted:

But no natural action at all can be explained by these substantial forms, since their defenders admit that they are occult and that they do not understand them themselves. If they say that some action proceeds from a substantial form, it is as if they said that it proceeds from something they do not understand; which explains nothing. So these forms are not to be introduced to explain the causes of natural actions.

We may call this, the explanatory impotence argument. Substantial forms were individuating principles that once joined with specific parcels of prime matter made them into substances with a specific causal profile. So, for instance, the substantial forms of hard bodies was different from the substantial form of fluid bodies and this primitive difference explained their different powers. But for Descartes no explanation of the difference is thereby achieved: the difference is simply posited as a primitive fact. For him, the only difference between hard bodies and fluid bodies is "that the parts of the one can be separated from the whole much more easily than those of the other" $(1998,10)$. This is supposed to amount to a genuine explanation of why there are two distinct kinds of qualities-hardness and fluidity - the difference being grounded in the microparts of bodies and their motions. Instead of taking these qualities as primitive, Descartes explains them by showing that they are different species of motion of the particles of matter. Here is how he put it:

If you find it strange that, in explaining these elements, I do not use the qualities called 'heat', 'cold', 'moistness', and 'dryness', as the Philosophers do, I shall say that these qualities appear to me to be themselves in need of explanation. Indeed, unless I am mistaken, not only these four qualities but all others as well, including even the forms of 
inanimate bodies, can be explained without the need to suppose anything in their matter other than motion, size, shape, and arrangement of its parts $(1998,18)$.

The directedness problem: how can a physical quality be directed to another? This was, in many ways, the more puzzling feature of powers. MedievalAristotelian powers were endowed with esse-ad. This was supposed to show how "one thing receives something from another or confers it upon the other" (Aquinas) without the qualities of each thing being shared by the other. But the puzzle was precisely how a quality can be intrinsic to a subject and 'bear' on another. For Descartes, this relatedness can only be a feature of minds and their content: only minds can be directed towards anything. Hence, either matter should be endowed with minds or there can be no such thing in matter as 'being directed to an effect'. The first horn is precisely the one Descartes dismissed by what came to be known as 'the little souls argument'. In a letter to Mersenne, (26 April 1643) he noted:

I do not suppose there are in nature any real qualities, which are attached to substances, like so many little souls to their bodies, and which are separable from them by divine power. Motion, and all the other modifications of substance which are called qualities, have no greater reality, in my view, than is commonly attributed by philosophers to shape, which they call only a mode and not a real quality $(1991,216)$.

The reference here is to the medieval idea that qualities can exist independently of substances. But what's interesting is that Descartes takes it that these qualities were endowed with directedness as if they were soul-like entities. As he explained in a letter to Princess Elizabeth, 21May 1643, real qualities were conceived by means of notions that were used "for the purpose of knowing the soul" (1991, 219). Gravity, one of Descartes's favourite examples, is a case in point. Descartes noted that instead of taking the view that heaviness is a kind of motion which is "produced by a real contact between two surfaces" $(1991,219)$, his medieval predecessors, starting from the "inner experience" of how the soul operates on bodies, took it that heaviness is a real quality "of which all we know is that it has the power to move the body that possesses it towards the centre of the earth" $(1991,219)$, thereby wrongly attributing to it soul-like attributes. Speaking critically of his former self in the sixth set of replies he noted that he too used to ascribe to gravity some kind of directed power to carry bodies towards the centre of the earth "as if it had some knowledge of the centre". But he changed his mind when he realised that this was tantamount to applying mind-like properties to gravity; for this directedness "surely could not happen without knowledge, and there can be no knowledge except in a mind" (1984, 298).

The motive force problem: How can a body move itself or another body? This question was thrown into sharp relief by Nicolas Malebranche who concluded that the only motive power is (in) God. According to a widely accepted account of God's action, God continuously annihilates and re-creates everything there is. When God wills a body A to come to existence, he wills it to be in a specific space a at a specific time $t$. How, then, Malebranche asks, can the body A move from point a to another point b all by itself? Or how can it be moved by the 'power' of another body B? In either case (self-motion or motion-by-other) the required 
power would 'supersede' the power of God, who willed body A to be in point a. Since nothing can supersede God's power, only God has the power to move a body. Malebranche concluded that "there is a contradiction in saying that one body can move another", since "no power, however vast it may be imagined to be, can surpass or even equal the power of God"; "no power can transport [a body] whither God does not transport it, nor fix or keep it where God does not fix or keep it, if it is God alone who adapts the efficacy of His actions to the ineffective actions of His creations" (Dialogues on Metaphysics 7, X; 1923, 189).

Arguments such as the above cast considerable doubt on the idea that matter is powerful. But if there is no power in matter, what options are available? Laws of nature replaced powers as principles of connection between distinct existences. But laws did not replace necessity. Instead, they captured the necessity that was taken to be grounded in powers. But how do laws acquire their necessity and what kind of necessity is this? ${ }^{6}$

\section{Cartesian Laws}

In Descartes's Principia, which appeared in 1644, God is the primary cause of all motion. But laws of nature become themselves the particular causes "by which individual parts of matter acquire movements which they did not previously have" (Part II, 36; 1982, 58). They account for changes of states of motion of bodies: "the rules or laws of nature (...) are the secondary and particular causes of the diverse movements which we notice in individual bodies" (Part II, 37; $1982,59)$. But what does that mean? How can laws be secondary causes?

To answer this question let us first take a look at Descartes's three laws of motion. In the Cartesian picture of things, God created matter in motion and rest "and now maintains in the sum total of matter, by His normal participation, the same quantity of motion and rest as He placed in it at that time" (Part II, 36; $1982,58)$. Throughout his work, this is a fundamental idea: the conservation of the total quantity of motion placed in nature by God initially. This is not a law-it is a governing principle. It follows directly from the immutability of God. In fact, it can be said that this Principle of Conservation of the Quantity of Motion (PCQM) is simply a facet of God. ${ }^{7}$ Note that God might not have chosen to put matter in motion. Hence, PCQM depends on God's Will in the sense that He willed to set matter in motion. But given this volition, PCQM is metaphysically necessary. God being immutable, PCQM has to hold is all possible worlds in which matter is in motion.

The three fundamental laws of nature are grounded in PCQM, that is in the immutability of God. They are part of the fabric of the world. Given his will to set matter in motion, PCQM and the fundamental laws are a constitutive part of nature: they follow from his immutability. Everything that happens in nature is subject to them. Motion, in other words, is regulated by God via laws, subject to an overall PCQM. Descartes says: "because God moved the parts of matter in

\footnotetext{
${ }^{6}$ For lack of space I do not discuss Descartes's account of laws and power in Le Monde. Suffice it to say that it is arguable that Descartes changed his position in moving from Le Monde to his mature work Principia. Briefly put, in Le Monde laws play a causal role, but matter is causally active too. For further discussion, and for what I take it to be the right account of the transition from Le Monde to Principia, see Ott (2009, 55ff).

7 For some similar thoughts see Garber (2013).
} 
diverse ways when He first created them, and still maintains all this matter exactly as it was at its creation, and subject to the same law as at that time; He also always maintains in it an equal quantity of motion" (Part II, 36; 1982, 58). Then come the three laws.

The first law: "that each thing, as far as is in its power, always remains in the same state; and that consequently, when it is once moved, it always continues to move" (Part II, 37; 1982, 59).

For Descartes motion and rest (lack of motion) are two distinct states of matter. Rest (change of state of motion to Rest) requires external agency (collision). Nothing moves from being in motion to being in lack of motion (Rest) "by virtue of its own nature" because this would mean that it would move "toward its opposite or its own destruction". This is the justification of the first law. Descartes notes that this law "results from the immutability and simplicity of the operation by which God maintains movement in matter" (Part II, 39; 1982, 60). What's important to add here is that Descartes explicitly denies that bodies are endowed with tendencies or capacities to change their state of motion "by virtue of their own nature" (Part II, 37; 1982, 59).

The second law: "that all movement is, of itself, along straight lines; and consequently, bodies which are moving in a circle always tend to move away from the center of the circle which they are describing" (Part II, 39; 1982, 60).

This law captures the idea that circular motion is "forced" or "constrained motion": it is deviation from the straight path due to the encounter of other bodies or due to the rigid connections among the parts of a body (as in the motion of a wheel). Descartes's justification is based directly on the immutability of God and the simplicity of his operations. This law too, he says, "like the preceding one, results from the immutability and simplicity of the operation by which God maintains movement in matter" (Part II, 39; 1982, 60). The appeal to immutability of God is essential because God maintains motion in matter as it is at every single moment. He maintains movement in matter "precisely as it is at the very moment at which He is maintaining it, and not as it may perhaps have been at some earlier time" (Part II, 39; 1982, 60). But the motion at each instant (or moment) is along a straight line. Though "no movement is accomplished in an instant", Descartes considers it obvious that "every moving body, at any given moment in the course of its movement, is inclined to continue that movement in some direction in a straight line, and never in a curved one" (Part II, 39; 1982, 60). Simplicity, however, is important, because motion along a straight line is simpler than curvilinear motion. From this law, Descartes says, it follows that "any body which is moving in a circle constantly tends to move [directly] away from the center of the circle which it is describing". Hence, the centrifugal tendency of a rotating stone in the sling is grounded in the second law.

The third law: "that a body, upon coming in contact with a stronger one, loses none of its motion; but that, upon coming in contact with a weaker one, it loses as much as it transfers to that weaker body".

Descartes proves the third law by appealing to the immutability of God. In the creation, God gave motion to particles and caused some of them to collide with other. Because he is immutable, he conserves motion in particles; hence the total quantity of motion, including this which is transferred from one particle to another, remains the same: "in now maintaining the world by the same action and with the same laws with which He created it, He conserves motion; not 
always contained in the same parts of matter, but transferred from some parts to others depending on the ways in which they come in contact" (Part II, 42; 1982, 62).

How then are laws the "secondary and particular causes of the diverse movements which we notice in individual bodies" (Part II, 37; 1982, 59)? Given that bodies were set in various states of motion in the beginning, laws cause (i.e., determine) their subsequent states. Why does X move in a straight line? Because it is a law that it must keep moving (it won't change its state of motion) until something stops it (First law). In this sense, the law is a cause of the movement of $\mathrm{X}$, since it dictates (determines) its motion. Similarly, why does X stop moving? (or why does X change its state of motion?) Because it is a law that X must change its state of motion if it collides with another body Y. Hence, change of the state of motion of X is a law-governed collision with another body Y (Third law). Finally, why does X move in a curved path? Not because "it is inclined to any circular movement"; but because it is a law that motion along curved path AB is forced motion, that is it consists in a deviation from the straight line (Second law).

It is striking that in the Principia, there is no reference to the dispositions of matter as causes of the motion of the bodies alongside the laws of nature. ${ }^{8}$ To be sure, Descartes does talk about affections, but he states clearly that all dispositions [omnium affectionum] of matter arise out of the movements of its parts; hence there are no sui generis (non-mechanical) dispositions (cf. Part II, $23 ;(1982,50)$. He explicitly states that when he uses expressions such as "striving [conatus] of inanimate objects toward motion", he does not attribute any thought or intention to them; he simply means "that they are so situated, and so urged to move [ad motum incitatos], that they will in fact recede if they are not restrained by any other cause" (part III, 56; 1982, 112). And in IV.199, he sums up his view by saying that all natural phenomena are " nothing other than, certain dispositions [dispositiones] of size, figure, and motion \{of bodies\}" (1982, 282). So there is no reason to think that for Descartes the references to dispositions, affections and the like in the Principia are nothing other than the (passive) mechanical qualities of the corpuscles of matter.

In fact in Principia, forces and generic powers of matter are fully replaced by laws. ${ }^{9}$ In a characteristic passage in II.43, Descartes states that "the force of each body to drive or to resist consists" in the body's obeying the first law of motion-

\footnotetext{
${ }^{8}$ In Le Monde Descartes notes that though when it comes to rectilinear motion, it is fully determined by the first two laws and God's conservation of things the way they are, in the case of circular motion, an extra explanatory principle is required, viz., the dispositions of matter. This explains why though the parts of a body tend to move in straight line, the body as a whole moves in a circle. Here is how he put it $(1998,30)$ : "According to this rule [the third law of motion], then, we must say that God alone is the author of all the motions in the world in so far as they exist and in so far as they are straight, but that it is the various dispositions of matter that render the motions irregular and curved. Likewise, the theologians teach us that God is also the author of all our actions, in so far as they exist and in so far as they have some goodness, but that it is the various dispositions of our wills that can render them evil".

${ }^{9}$ Here I am in agreement with Garber $(1992,298)$ who takes the line that Cartesian forces are nothing but ways of talking about how God acts on bodies in a lawful way. But, as it will become clear later on, I add to Garber's account that, strictly speaking, Descartes replaces forces with laws in the sense that there is nothing more to the content of force-talk than whatever is involved in the law-governed motion of bodies. For more on the various accounts of force in Descartes see Garber (1992, chapter 9), Ayers (1996) and Ott (2009, chapter 8).
} 
period $(1982,63)$. Descartes says that the "force of each body to act against another or to resist the action of that other consists" (...) "in the single fact that each thing strives, as far as is in its power, to remain in the same state, in accordance with the first law stated above" (op.cit.). Forces of action or resistance are replaced by law-like behaviour.

Here is a summary of the main features of Cartesian laws.

Laws are difference-makers: all phenomena in nature are counterfactually dependent on laws. If the laws had been different (per impossibile), the world would have been different.

Laws are counterfactually robust: No matter what the initial arrangement of particles in motion, the laws are such that the effect would be the same. Which effect? The world as we know it.

Laws are metaphysically necessary: God agitated the different parts of matter in diverse ways, but then He "did no more than sustain nature in His usual manner leaving it to act according to the laws He has established". These laws are such that "even if God had created many worlds, there could be not be any in which they could have failed to be observed" $(1998,31)$.

Laws are immanent: they directly follow from God's immutability. Laws are causal principles: the motion of the various bodies in the world happen because of them and not simply according to them.

The passivity of matter, however, created a potential tension in the Cartesian system: How are laws executed by matter? If matter is inert and lacks any motor force, how is it that pieces of matter are subjected to the causal action of laws? Descartes is clear that bodies have "no innate tendency to motion" (Part III, 26; $1982,94)$. Nor do they have any "tendency towards rest" (Part II, 37; 1982, 59). All action is by contact and requires a mover. He therefore puts forward seven rules by virtue of which the collision of bodies is regulated.

Though these rules were have ben found wanting, the relevant point here is that Descartes introduces them as rules which "determine to what extent the movement of each body is changed by coming in contact with other bodies" (part II, $45 ; 1982,64)$. This way to formulate the task is fully consistent with the claim that matter is passive and hence that rules (laws) determine how (the quantity of) motion is redistributed among the colliding bodies. But in showing how these rules apply to contacts among moving bodies Descartes stated that "it is only necessary to calculate how much force to move or to resist movement there is in each body; and to accept as a certainty that the one which is the stronger will always produce its effect" (Part II, 45; 1982, 64). Hence, it is not clear, to say the least, that Descartes has a coherent view about how matter is capable to act on matter and be acted upon by matter. In a latter to More (August 1649), Descartes noted that a created substance can have the power to move a body; but this is a mode of the created substance conferred on it by God (cf. 1991, 381). Still can motion be transferred from one body to another? If motion is a mode of the thing moved (as it certainly is), then it cannot since no mode can be transferred from one body to another. But as we have already seen, Descartes repeatedly talks as if motion is being transferred from one body to another because of the laws of motion.

In Principia (II, 25; 1982, 51) Descartes defined motion as 
immediately contiguous to it and considered as at rest, into the vicinity of [some] others. (...) I also say that it is a translation, not the force or action which transfers [non vim vel actionem quae transfert], in order to show that this motion is always in the moving body and not in the thing which moves it (because it is not usual to distinguish between these two with sufficient care); and in order to show that it is only a mode [of the moving body], and not a substance, just as shape is a mode of the thing shaped, and rest, of the thing which is at rest.

In this critical passage, he distinguished clearly between motion as translation [i.e., change of relative place] and motion as force or action which is transferred from one body to another. But in many other places in the Principia Descartes talks freely of the 'transference' on motion (see e.g., II, 40 \& 42). A charitable reading of Descartes would be this. Strictly speaking, there is no transfer of motion between bodies (though, loosely speaking their collisions can be described as if there were transfer). Still, when bodies collide with each other, the quantities of motion they already possess are re-distributed among them according to the relevant laws (and always in line with the overarching principle PCQM). The laws then are the (particular and secondary) causes (differencemakers) of the re-distribution of particular quantities of motion, since without them there would be no fact of the matter as to what would happened in the collision.

\section{Occasionalist Laws}

The occasionalist reaction to Descartes was based on the thought that if matter is truly inert and lacking of any motive power, then the only real (and direct) cause should be God himself. For Malebranche, we have no conception of power of secondary things. If the only motive power is (in) God, how does God act on matter? The answer is clear: via laws. God acts via laws because his action is uniform and simple; it "link(s) together the parts which compose the world" and makes the world knowable $(1923,190)$. Hence, laws are willed by God. Laws are principles by means of which God acts in nature and establishes its uniformitywhich is a facet of its perfection.

For Malebranche, God submits to laws not by absolute necessity but by desire (Treatise on Nature and Grace (TNG), XXI; 1992, 119). Being omnipotent, God could have created an infinity of possible worlds. Hence, there could have been a law-less (disorderly) world. But God did not desire to create such a world; hence, he did not will it. God created an orderly world, governed by the simplest laws since He acts "always by the simplest ways" (TNG, XVII; 1992, 118). In fact, of all the possible (law-governed) worlds, he willed to create "that world which could have been produced and preserved by the simplest laws, and which ought to be the most perfect with respect to the simplicity of the ways necessary to its production or to its conservation". (TNG, XIII; 1992, 116) So perfection is a function of the simplicity of the ways the world could have been created and conserved. As he says later on: "if he had been able (by equally simple ways) to make and to preserve a more perfect world, he would never have established those laws" (TNG, XXII; 1992, 120).

Unlike Cartesian laws, Malebranchean laws are not grounded in the immutability of God but in his Will and, in particular, in his ways of acting. He always acts in the simplest ways and He always acts (in the natural order) with general laws (volitions). God wills certain laws "because of their fruitfulness". 
(TNG, XIX; 1992, 119)

What then are the laws of nature? They are God's general volitions. They are his decrees. As such, the laws of nature are not metaphysically necessary. The decrees (laws) of God are only ex hypothesis necessary. Hence, the question 'Can God change the laws?' admits of a positive answer. Like Descartes, Malebranche thought that God could have not set matter in motion (if he had wished not to produce anything new in the world). But in addition, God might will that the actual laws of motion change (if, for instance, he wills to create incorruptible bodies).

Though laws could be different (or could change, if God willed it), they are constant and immutable and they hold everywhere and everywhen. He couldn't be more explicit: "The laws of nature are constant and immutable; they are general for all times and for all places" (TNG XVIII; 1992, 118). In fact, it is the very constancy and immutability of laws that explains why in nature there are unwanted (or undesirable) effects-e.g. hail destroys a harvest or a malformed baby is born. For Malebranche, it is not that God willed, with a particular volition these particular effects to happen. Rather, these effects are the "necessary consequences" of the laws of communication of motion he had initially established (TNG, XVIII; 1992, 118). God desires that "all of his creatures should be perfect" (op.cit.); But he acts by general laws which he foresees to be the most fecund (cf. TNG, XXII; 1992, 119). These are also the simplest laws. Precisely because God acts in the simplest ways, it would be "unworthy of his wisdom to multiply his wills in order to stop certain particular disorders". Hence, simple and general laws 'cover' everything that happens in nature, within the natural (i.e., not miraculous) order.

The two fundamental laws of nature are laws of motion:

The First Law: "that moved bodies tend to continue their motion in a straight line"; (TNG, XV; 1992, 117)

The Second Law: "that when two bodies collide, their motion is distributed both in proportion to their size, such that they must afterwards move at an equal speed" (TNG, XV; 1992, 117).

According to the second law, what happens in collisions is the re-distribution of motion "in proportion to their size". As Malebranche noted this law is not observed in experience; but he noted that it is a true law holding in the "invisible" bodies" (TNG, XVI; 1992, 117).

In Dialogues on Metaphysics (Dialogue 7, XI), the first law of motion was justified on the grounds that the straight line is the simplest and shortest line. When it comes to the second law, he noted that though there is change of direction, there is conservation of the "quantity of the moving force" $(1923,191)$. These two principles constitute "the general laws of the communication of movements in accordance with which God acts incessantly" (op.cit) (cf. also Researche, Elucidation XV; 1997, 664).

Malebranchean laws of nature are "efficacious"; 10 in particular, it is because of the efficacy of the second law (governing impact) that diversity in matter is produced: the diversity there is in matter is counterfactually dependent on the second law of motion. But more than this, both laws are the cause of all motion: "These two laws are the cause of all the motions which cause that variety of

${ }^{10}$ As Robert Merrihew Adams $(2013,75)$ aptly put it, Malebranchean laws “have 'oomph"”. 
forms which we admire in nature" (TNG, XV; 1992, 115). They are "necessary to the production and the preservation of the earth, and of all the stars that are in the heavens" (op.cit.). Whatever happens in nature (barring God's miraculous intervention) is the necessary consequence of the laws of motion.

But how are laws executed by matter? For Malebranche, they are not! God himself executes the laws. The laws are the divine decrees themselves, which ground the regularity. The laws are principles of connection ("indissoluble bonds of union") between natural things (distinct existences). As he put it in Dialogue 7, XIII $(1923,195)$ : "the divine decrees are the indissoluble bonds of union between the various parts of the universe and of the marvelous network of all the subordinate causes".

As Malebranche stressed, the two basic principles of what came to be known as occasionalism are these:

1. Bodies lack motor force.

2. God acts on nature via general laws.

Here is how he put it:

these two principles, of which I am convinced, that none but the Creator of bodies can be their mover, and that God communicates His power to us only through the establishment of certain general laws, the realisation of which we determine through our various modifications (Dialogues, 7, XIV; 1923, 196).

Since matter is impotent to execute the laws, they must be 'executed' by God; yet, as is explicitly stated in the foregoing passage, the laws are 'realised' in various natural (i.e., occasional) causes (via their modifications). In this scheme, there is no room for connecting entities like powers/active qualities. The link between God (as the only power) and the regularity there is in nature is laws-that is God's decrees which are directly realised in natural bodies and their motions (cf. Dialogues 7, XIII; 1923, 195). Hence, laws being the "indissoluble bonds of union between the various parts of the universe" are executed by God and are realised in natural bodies and their regular behaviour.

How are laws executed by God? When He re-creates a body in motion, $\mathrm{He}$ makes it move always in a straight line according to the first law, i.e., the subsequent re-creations should be in accordance to the first law. This is God's general volition. But there are collisions. Again, the law of collisions determines that the re-created bodies will be such that there is a certain re-distribution of motion among them. In a collision between body $\mathrm{X}$ and body $\mathrm{Y}, \mathrm{X}$ is not the cause of the motion of Y.X communicates "nothing of its own" to Y. Yet, there is a lawgoverned re-distribution of motion between X and Y. God acts according to a law which causes the re-distribution of motion. Hence though all communications of motion are executed by God, they are executed by a general law. The action of natural causes consists "only in the motor force activating them", i.e., God (Researche, Elucidation XV; 1997, 662). Does that mean that God communicates his power to bodies? Not quite! God has made the modifications of bodies the occasional causes of his action-which is law-governed (cf. 1997, 225).

There is an ongoing debate among Malebranche's scholars about the content of laws of nature-are they general volitions or (sums of) particular volitions? ${ }^{11}$

\footnotetext{
11 See Pessin 2001; Ott 2009, chapter 11; Nadler 2011; Robert Merrihew Adams 2013 for a representative sample.
} 
As Malebranche explains, when God acts with a particular volition, he acts without the occasional cause, e.g., when I feel pain without being pricked by a pin. Or when a body "begins to move itself without being struck by another, or without any change in the will of minds, or in any other creature that determines the efficacy of some general laws, I say then that God moves this body by a particular will" (TNG, Illustration II; 1992, 195). But what happens when a ball strikes another? How does God act? Malebranche's answer is that God moves the second ball by a general volition (a general law). The ball is moved "in consequence of the general and efficacious laws of the communication" (cf. also TNG, Illustration I; 1992, 195). So it seems correct to say that Malebranchean laws are general volitions.

Malebranchean laws of nature are not metaphysically necessary. But are they contingent? They are not. As we have seen, God submits himself to laws not out of absolute necessity but out of his will for the good. Malebranche also stresses that, to put it in modern jargon, regularity does not imply causation; necessity is also needed. Hence, "Only in the wisdom of God do we see eternal, immutable, and necessary truths. Nowhere else but in this wisdom do we see the order that God Himself is constrained to follow (Recherche; Elucidation 10; 1997, 615-6). In a famous passage in his La recherché de la verite, Malebranche makes clear that we can conceive of absolute (metaphysical) necessity only between the will of God and something happening because of this:

A true cause as I understand it is one such that the mind perceives a necessary connection between it and its effect. Now the mind perceives a necessary connection between the will of an infinite being and its effect. Therefore, it is only God who is the true cause and who truly has the power to move bodies $(1997,450)$.

Since there is no perception by the mind of necessary connections between natural (or occasional) causes and natural (or occasional) effects, these are not real causes. For any natural cause, it is conceivable without contradiction that it can occur without its effect. And of course, God can make it happen that that it does occur without its (natural) effect. Only in the case of God's will is it impossible for us to conceive of it without at the same time conceiving whatever it wills to happen. But, barring miraculous interventions, natural causes invariably precede their natural effects in virtue of God's general volitions, aka laws of nature. Hence, the regularity there is in nature (in virtue of which it is predictable and knowable) is grounded in (in the sense of being the effect of) the laws of nature. The law is not the regularity itself, but it is the principle (God's general volition) which grounds the regularity.

The occasional cause does not act-though it might seem to us that it does. It is the law that is causally efficacious: "A body moves immediately after having been struck: the collision of the bodies is the action of the occasional cause; thus this body moves by a general will" (op.cit.). Occasional causes and the concomitant regularity is a sign that the effect does not have "something singular about it". Hence, the presence of an occasional cause is sign ("mark") that there is action by the general volition of God (Illustration VIII). Hence, regularity (occasional 'causation') is a 'mark' for the presence of a law by means of which God acts.

Being the decrees of God, laws hold with some kind of necessity. Recall the very title of Malebranche's Treatise: On the Necessity of General Laws of Nature. 
What kind of necessity is this? It is natural or hypothetical necessity. Even though the natural necessity of the laws cannot possibly be rationally inferred from the observation of the invariable conjunction of natural causes and natural effects, it can be conceived if we reflect on the way God acts. The laws of nature are certainly part of the fabric of nature; hence, there is necessity in nature; though this necessity is not located or grounded in bodies "by themselves"; nor can it inferred by experience and from the regularity there is in nature. ${ }^{12}$

\section{Berkeley on Laws}

That laws are naturally necessary is a view that, perhaps surprisingly, can be attributed to Berkeley too. For Berkeley, all causation is an action of the will of a spirit. Hence, only God and minds (spirits) can be (efficient) causes. Ideas are passive and inert (Principles $\S 25 ; 2008,92$ ). Though it is false to claim that ideas are the "effects of powers resulting from the configuration, number, motion, and size of corpuscles", ideas must nonetheless have a cause "whereon they depend, and which produces and changes them" (Principles $§ 26 ; 2008,92)$. These can only be incorporeal substances (i.e., minds qua active substances).

God excites (and causes) ideas in us by means of laws of nature. This claim is grounded in the fact that ideas have "admirable connexions" and regularity; they come "in a regular train or series" (Principles §30). So the order and regularity in the co-occurrence and succession of ideas suggest that they are caused in us by a Will which acts in an orderly and regular way. As Berkeley put it: "The set of rules or established methods, wherein the mind we depend on excites in us the ideas of sense, are called the 'laws of nature'; and these we learn by experience, which teaches us that such and such ideas are attended with such and such other ideas in the ordinary course of things" (Principles $§ 30 ; 2008,94)$.

Laws of nature stem from God's Will. They are expressions of God's Will to act in a regular way: "(T)his consistent uniform working, which so evidently displays the goodness and wisdom of that governing spirit whose will constitutes the laws of nature" $(\S 32 ; 2008,94)$. But unlike all of his predecessors, Berkeley took it that laws of nature are known by observation and empirical study. They are not known a priori. They are not inferred by reference to the simplicity of God's actions or his immutability. They do reflect his goodness and wisdom in creating the world, but they can only be known a posteriori. In particular, laws are not discovered a priori by looking for "necessary connections among ideas". There is nothing in the idea of fire that necessarily implies that it warms us. The regularity there is in the world is discovered empirically "only by the observation of the settled laws of nature" $(\$ 31 ; 2008,94)$. Thanks to the laws of nature, ideas are connected to each other (e.g., the idea of fire and the idea that it warms us) even though one may be conceived without the other without falling into contradiction.

In a certain sense, Berkeley pushed the case for occasionalism to its extremes. Malebranchean occasionalism kept matter but divested it from any causal power or efficacy. Hence, there are no corporeal causes. Without naming it, Berkeley (Principles §53) noted that occasionalism got it right in claiming that "amongst

\footnotetext{
12 Here I am in essential agreement with Robert Adams who stresses that for Malebranche there is necessitation in causation in the following sense: occasional causes are "part of how God's general volitions, as efficacious laws of nature, necessitate particular effects" $(2013,77)$.
} 
all the objects of sense, there was none which had any power or activity included in it, and that by consequence this was likewise true of whatever bodies they supposed to exist without the mind" $(2008,103)$. But he thought that the further supposition, viz., that there is "an innumerable multitude of created beings, which (...) are not capable of producing any one effect in nature" is "unaccountable and extravagant", though possible.

If Berkeley found in occasionalism no argument for the philosophical category of mater, he found in it an understanding of how God acts in the world: via laws of nature. In this sense, laws of nature are key to Berkeley's natural philosophy. As he put it (Principles $§ 62 ; 2008,107)$ :

\begin{abstract}
There are certain general laws that run through the whole chain of natural effects. These are learned by the observation and study of nature, and are by men applied as well to the framing artificial things for the use and ornament of life as to the explaining the various phenomena: which explication consists only in showing the conformity any particular phenomenon has to the general laws of nature or, which is the same thing, in discovering the uniformity there is in the production of natural effects, as will be evident to whoever shall attend to the several instances, wherein philosophers pretend to account for appearances.
\end{abstract}

This rich passage suggests the following about laws:

a) Laws "run through" the whole chain of natural effects. Hence, laws cover all natural effects (the whole chain of events in nature). This covering should not be seen as 'governing' but as 'running through'-laws 'permeate' natural phenomena; the imbue natural phenomena.

b) These laws, as noted already, are discovered a posteriori; they are learned by observation and empirical study of nature.

c) Explanation in natural philosophy is showing that particular phenomena conform to a general law; that is, that they are 'permeated' by a law. Hence, explanation can be seen as nomological subsumption.

d) The 'production' of natural effects is nothing more than their law-based explanation-that is, their permeation by laws.

God acts via laws at all levels. And because of this, he produces (literally this time, since He's an efficient cause) any effect "according to the standing mechanical laws of nature" (op.cit.). As Berkeley repeatedly stresses, this is not a necessary truth-it is not "absolutely necessary" for God to produce any effect by mechanical principles. Yet, the metaphysical contingency of the 'clockwork of nature' does not detract from the fact that God wills to act "agreeably to the rules of mechanism". In fact, given that Berkeley does want to accommodate mechanism (the clockwork of nature) within his philosophy, he further argues that although God could produce anything he wanted without any mechanism, the 'clockwork of nature' is the way God has chosen to produce effects in nature in a regular and orderly way. Hence, the mechanical laws of nature are conditionally or naturally necessary, viz. necessary "to the producing [of an effect] according to the standing mechanical laws of nature".

In De Motu, in which Berkeley makes an attempt to explain his natural philosophy without explicitly denying that there is matter, he expresses his firm view that " $(\mathrm{R})$ egarding body we may boldly declare as established fact that it is not the principle of motion" $(2008,250)$. He adds that what we know about the 
body (what is contained in the idea of body-"extension, solidity, and figure") is not a principle of motion. And in $\$ 24$ he dismisses that there might be something unknown in body which is this principle of motion, because we have no idea of it.

Laws of nature, then, 'replace' internal principles of motion of bodies. In science it is enough to state true theorems about the motion of the bodies, irrespective of what might or might not cause these motions. These true theorems are "the rules and laws of motion" and the "theorems deduced from them", (regulis \& legibus motuum, simul ac theoremata inde deducta). And these laws "remain unshaken, so long as sensible effects and reasoning based on them are granted" $(2008,252)$. There is little doubt, however, that even though laws are discoverable a posteriori, they hold with natural necessity and permeate the actual behaviour of things.

\section{Leibniz on Laws and Powers}

Malebranche did adopt the principle of the conservation of total quantity of motion. In Dialogue X, $(1923,267)$, he noted: "In a word, God has chosen the simplest law on the basis of the unique principle that the stronger shall conquer the weaker; and, subject to this condition, that there shall always be in the world the same quantity of motion". But he never followed the Cartesian course of trying to ground the laws of motion on this principle and the immutability of God. He did attribute "moving force" to God and claimed that God acts "always with the same efficacy or the same quantity of moving force" (Dialogue 7; 1923, 191). The total quantity of moving force is conserved, since as Malebranche put it, God "never changes the quantity of the moving force which animates matter" (op.cit).

As is well known, a principled disagreement between the Cartesians and Leibniz concerned what exactly is conserved during impact. Already in 1686, Leibniz noted that there is a great difference between the concept of the quantity of motion and the concept of quantity of motive force and that Descartes was mistaken in holding them to be equivalent. This mistake led Descartes, Leibniz argued, to "to assert that God conserves the same quantity of motion in the world" $(1989,296)$. But this basic Cartesian principle PCQM was not correct, as Leibniz conclusively demonstrated. What is conserved is the total quantity of vis viva, which is the product of mass times the square of the velocity of a body. As Leibniz put it, what is conserved is the "total force and the total direction". We will not go into the details of this presently. What is important for our purposes is that Leibniz presents this principle-the conservation of the quantity of force-as a subordinate law of nature (Discourse on Metaphysics, §17).

The fundamental law of nature is a law of order. The world is orderly and regular and for Leibniz "no matter how God might have created the world, it would always have been regular and in a certain general Order" (Discourse §6; $1989,306)$. Hence, this fundamental law is metaphysically necessary. But the most orderly world could have been the most complex one. Leibniz notes that God chose to create the most perfect world, where perfection is a function of two factors-simplicity and strength. As he put it: "But God has chosen that world which is the most perfect, that is to say, which is at the same time the simplest in its hypotheses and the richest in phenomena" (op.cit.). So the simplest world is at the same time the most comprehensive world.

This world is structured by subordinate laws. These are God's general 
volitions. They govern everything without exceptions: "For the most general of God's laws, which rules the whole sequence of the universe, is without exception" (Discourse $\S 7 ; 1989,307$ ). The law of the conservation of the quantity of force is the chief subordinate law of nature. It is grounded directly in God in that it is God who "always conserves by rule the same force" (Discourse $\S 17$; $1989,314)$. Elsewhere $(1989,499)$, he calls the Law of conservation of quantity of force "the foundation of the laws of nature" implying that among the subordinate laws there is a hierarchy of laws, with PCQF being at the bottom.

But what is force or active power? Leibniz takes it to be a non-mechanical quality, which is necessary for explaining the behaviour of things. It is nonmechanical in the sense that it is not one of the basic mechanical categories of Cartesianism, viz., extension, figure and motion. It's not geometrical and it is attributed to natural bodies over and above their mechanical affections. In fact, given that the basic law of nature is the conservation of the quantity of force, Leibniz argues that in finding the "true laws of nature and the rules of motion", we have to go beyond mechanics and physics to metaphysics (Discourse $§ 18$; 1989,315 ). We have to ascertain the forces (that is the "immediate causes" of motions and changes in nature). Forces are "more real" than their effects (changes in motion) and because forces are "different from size, figure, and motion", we can conclude that "not everything which is conceived in a body consists solely in extension and its modifications" (op.cit.). Leibniz took the need to appeal to forces to vindicate the medieval-Aristotelian view that bodies have active and passive powers, which are not mechanically explicable and grounded. Rather, they "pertain to certain forms or indivisible natures" of corporeal substances (op.cit.). The key characteristic of forces, which are directly "implanted" to corporeal bodies "by the Creator", is that by being subjected to forces, bodies are endowed "with conatus, attaining [their] full effect unless [they are] impeded by a contrary conatus" $(1989,440)$. This force is in the "bodies themselves" and "it constitute(s) the inmost nature of the body, since it is the character of substance to act" $(1989,435)$.

Restoring forces or powers as being inherent in bodies was an important break with Cartesianism. Matter is not passive but active. But Leibniz adopted the idea that the motions of pieces of matter is subject to natural laws, which are established by God. Though not metaphysically necessary, the laws are far from "arbitrary". God has chosen them but as Leibniz put it, "God has been led to set in motion the laws which are observed in nature through determined principles of wisdom and by reasons of order" $(1989,500)$. In this sense, we can say that laws of nature are conditionally or naturally necessary in that given God's demand for simplicity and strength (i.e., perfection) in an orderly world, these particular laws had to be chosen. In a letter to Malebranche (June22/July 2 1679), he put this point thus: "We must also say that God makes the maximum of things he can, and what obliges him to seek simple laws is precisely the necessity to find place for as many things as can be put together; if he made use of other laws, it would be like trying to make a building with round stones, which make us lose more space than they occupy" $(1989,211)$.

His general reaction to occasionalism reveals his views about the relation between law and power. His chief point is that though occasionalists are right in denying that there is interaction among bodies, and in particular, in denying the direct influx theory according to which a cause is what flows into the effect 
(hence that something flows between two distinct substances), they are wrong in placing all action in God, thereby turning him into a Deus ex Machina.

Occasionalism, for Leibniz, introduces "a kind of continuous miracle" (1989, 338). It is "as if God as a rule interfered in some other way than by preserving each substance in its course and in the laws established for it" (op.cit.). Though his diagnosis of how God acts according to occasionalism might well be wrong, since for Malebranche at least God need not act by anything other than his general volition, Leibniz points to a genuine problem with occasionalism, viz., that laws are executed directly by God himself and not by natural bodies. So Leibniz took it that a complete understanding of the workings of nature requires both laws of nature and powerful substances. He identified a key problem for both Cartesianism and occasionalism. I call it Leibniz's problem: How can passive matter 'obey' laws? How are laws executed if matter does not have what it takes the execute them?

In his reply to Bayle's criticism in 1698, Leibniz stressed that even though general laws are decrees of God, they are in need "of a natural means of carrying [them] out"; hence, "all that happens must also be explained through the nature which God gives to things" $(1989,494)$. In his 'On the Nature itself, or on the Inherent Force and Actions of Created Things", (1698), Leibniz gave the following argument for the need to make bodies powerful and causally efficacious. Laws are certainly God's decrees; but for bodies to be able to execute the laws in the future, something must have been "impressed upon creatures" by God which makes them capable to act according to the law. For otherwise there are no necessary connections between causes and effects; the command (God's law) is either not binding at future moments or "it must always be renewed in the future". The command (the law), which was set in the beginning of time, is binding now and in the future only if "the law set up by God does in fact leave some vestige of him expressed in Things". And this implies that "there is a certain efficacy residing in things"; (and creatures in general). It is this efficacy which makes them "capable of fulfilling the will of him who commanded them". This efficacy is part of their nature and it's a force "from which the series of phenomena follows according to the prescription of the first command" (cf. 1989, 501).

Leibniz's argument implies that both laws and inherent powers are required for the explanation of natural phenomena. But powers are individuated independently of laws; they are presupposed for the existence of necessary connections in nature in the sense that powers are required for things to obey laws and for the laws to be binding. In his letter to Hartsoeker (Hanover, 10 February 1711), Leibniz makes clear that it is not enough for the identification of a power to state a law that it obeys (or simply that there is law); what is also required is the specification of the mechanism by means of which this power acts. The mechanism is, clearly, on top of the law and given independently of it. Without the mechanism the power is "an unreasonable occult quality". He says:

Thus the ancients and the moderns, who own that gravity is an occult quality, are in the right, if they mean by it that there is a certain mechanism unknown to them, whereby all bodies tend towards the center of the earth. But if they mean that the thing is performed without any mechanism by a simple primitive quality, or by a law of God, who produces that effect without using any intelligible means, it is an unreasonable occult quality, and so 
very occult, that it is impossible it should ever be clear, though an angel, or God himself, should undertake to explain it (in Newton 2004, 112).

The bottom line is that qua divine commands, laws are binding only if bodies are capable of following them necessarily-and this is grounded in their "impressed nature". Fundamentally, their impressed nature ("the substance of things itself", as Leibniz put it), "consists in the force of acting and being acted upon" $(1989,502)$. This is "a primitive motive force", which is "superadded" to extension and mass and grounds motion and action. For reason which we cannot go into here, Leibniz identifies this primitive force with a soul or substantial form.

\section{Hume and Newton on Laws and Necessity}

Recently, there has been considerable controversy about what Hume thought about necessity. The trend is to interpret his a sceptical realist, while the traditional view was that he was a denialist. For reasons that I cannot go into now, I think that the traditional view is essentially correct: Hume denied that there is any power in nature; hence he denied that there is any necessity in nature (see my 2003, chapter 1 for a discussion). Hume did not deny that there are laws of nature. However, these laws do not govern; nor is it the case that worldly things obey them, in any interesting sense. Laws are just the regularities themselves and nothing more. Reflecting on the question of necessity that the laws of motion allegedly have, Hume said:

The degree and direction of every motion is, by the laws of nature, prescribed with such exactness, that a living creature may as soon arise from the shock of two bodies, as motion, in any other degree or direction than what is actually produced by it. Would we, therefore, form a just and precise idea of necessity, we must consider whence that idea arises, when we apply it to the operation of bodies (Enquiry, Section VIII, Part I, 82).

The idea of necessity, which of course Hume never doubted that we possess and that it is part of the common understanding of causation, is a projection of the human mind on nature, which is conditioned by the existence of uniformity and regularity on nature:

Our idea, therefore, of necessity and causation arises entirely from the uniformity, observable in the operations of nature; where similar objects are constantly conjoined together, and the mind is determined by custom to infer the one from the appearance of the other. These two circumstances form the whole of that necessity, which we ascribe to matter. Beyond the constant conjunction of similar objects, and the consequent inference from one to the other, we have no notion of any necessity, or connexion (Enquiry, Section VIII, Part I, 82).

Newton's attitude, which of course preceded Hume's, was quite different. ${ }^{13}$ On my reading of Newton, there is power in nature but powers and laws are mutually determined-to introduce a power is to introduce a law. Interestingly, Newton did allow that there is necessity in nature; but this necessity is, from an empirical-scientific point of view, ineffable.

To substantiate the point that for Newton powers and laws are mutually determined, we should briefly compare him with Descartes. In Definition III of

\footnotetext{
${ }^{13}$ My understanding on Newton has been influenced by long discussions with Robert DiSalle.
} 
the Principia, Newton introduces the power (vis) of matter of resisting acceleration (change of state of motion) by means of a law. He says: "Inherent force of matter (vis insita) is the power of resisting by which every body, so far as it is able (quantum in se est), perseveres in its state either of resting or of moving uniformly straight forward" $(2004,60)$. Let's compare this with Newton's first law of motion: "Every body perseveres in its state of being at rest or of moving uniformly straight forward, except insofar as it is compelled to change its state by forces impressed" $(2004,45)$. The Definition defines a power a body has intrinsically, viz., the power to persevere in its state of motion (i.e., the power to resist changes in its state of motion), by stating the law it obeys quantum in se est. ${ }^{14}$ In the statement of the first law, on the other hand, Newton describes the law a body obeys by stating what happens to a body if the intrinsic power to persevere in its state of motion is the only one that is present and acting. i.e., if the body is quantum in se est. The definition has the direction from the power to the law; the law has the direction from the law to the power. A way to combine the two would be the following: Every body obeys the first law of motion (it perseveres in its state of being at rest or of moving uniformly straight forward) if and only its vis insita is the only power acting on the body. In this sense, a power is defined by the law the body that has it obeys; and conversely, a law states what a body does in virtue of a power it possesses. ${ }^{15}$

Descartes, by contrast, simply stated the law: "that each thing, as far as is in its power (quantum in se est), always remains in the same state; and that consequently, when it is once moved, it always continues to move" (II, 37; 1982, 59). In his case, as we have already noted, there is no power to be defined; the law simply replaces the power. Intrinsically. i.e., quantum in se est, the body obeys the law (it always remains in the same state of motion).

In the Preface to the second edition of the Principia in 1713, which was written by Roger Cotes under the close supervision of Newton, Cotes carefully distinguished Newton's views from those of the Aristotelians as well as from those of the Cartesians. The chief point made against the Aristotelians was that they posited sui generis powers and this was redundant and non-explanatory. Cotes wrote:

\begin{abstract}
There have been those who have endowed the individual species of things with specific occult qualities, on which - they have then alleged - the operations of individual bodies depend in some unknown way. The whole of Scholastic doctrine derived from Aristotle and the Peripatetics is based on this. Although they affirm that individual effects arise from the specific natures of bodies, they do not tell us the causes of those natures, and therefore they tell us nothing $(2004,43)$.
\end{abstract}

Note the complaint about the "unknown way" on which the operations of bodies possessing a certain power depend. Newton's emphasis on laws in defining powers was meant, among other things, to capture, and hence to explain, how powers act: they act via laws; better: to introduce a power is to introduce the law that things that possess it obey. There is no explanatory gap here. No unknown

\footnotetext{
14 For more on the importance of Quantum in Se Est see I. Bernard Cohen (1964).

15 As George Smith $(2002,151)$ nicely put it: "The law characterizing a force from a physical point of view gives its "physical proportions" and assigns it to a "physical species." Two forces are of the same physical species only if they are characterised by the same law".
} 


\section{modus operandi.}

But Cotes goes on to criticise the Cartesian way too. As is well-known, his chief point against the Cartesians in the preface was that they recourse to unfounded hypotheses and speculations about the mechanical causes of the phenomena. It transpires however that Cotes's real complaint was that they do all this in order to avoid the Aristotelian pitfall of powers. They try to rectify the sui generis and non-explanatory nature of Aristotelian powers by avoiding powers altogether and by appealing, instead, to mechanical hypotheses about matter in motion. Here is how Cotes puts the point when it comes to what Cartesians say about gravity:

For either they will say that gravity is not a property of all bodies - which cannot be maintained - or they will assert that gravity is preternatural on the grounds that it does not arise from other affections of bodies and thus not from mechanical causes. Certainly there are primary affections of bodies, and since they are primary, they do not depend on others $(2004,51)$.

Hence, the price that the Cartesian way out comes with is either a denial that gravity is a universal property of bodies or that gravity is a mysterious property (power) of things since it is not explained and grounded mechanically (i.e., by means of a law-obeying configuration of matter in motion). When then Cotes states that there are "primary affections of bodies", and that being primary, these affections (gravity being one of them) "do not depend on others", he carves out precisely the middle road that Newton suggested, viz., to introduce a primary affection of matter which is neither occult (as the Aristotelians would have it) nor mysterious (as the Cartesians would have it) one would have to introduce it by means of the law it obeys, even if this law was not mechanical. I take it then that Cotes's and Newton's via media was to keep both powers (against the Cartesians) and laws (against the Aristotelians) but to claim that they are introduced hand-in-hand-especially when it comes to the primary (and hence not-further-reducible) powers of matter.

Cotes makes this point (fairly) clearly when he talks about gravity being such a primary affection: "Among the primary qualities of all bodies universally, either gravity will have a place, or extension, mobility, and impenetrability will not. And the nature of things either will be correctly explained by the gravity of bodies or will not be correctly explained by the extension, mobility, and impenetrability of bodies" $(2004,50)$. Gravity is not an occult power (even though we may not know its cause) because, as Newton put it in the General Scholium, "it is enough that gravity really exists and acts according to the laws that we have set forth and is sufficient to explain all the motions of the heavenly bodies and of our sea" $(2004,92)$.

Hence, the Newtonian method, as explained by Cotes is a via media: "From certain selected phenomena they deduce by analysis the forces of nature and the simpler laws of those forces, from which they then give the constitution of the rest of the phenomena by synthesis" (emphasis added) $(2004,44)$.

Newton, as is well known, did allow that there might be an unknown cause of gravity. So he might be taken to have allowed that there might be ways to identify powers independently of the laws they obey. But he was adamant that this kind of independent identification, if possible at all, should not be taken as a requirement for a legitimate appeal powers; specifying the law that they obey is 
enough for scientific purposes. In an unsent letter written circa May 1712 to the editor of the Memoirs of Literature, Newton referred explicitly to Leibniz's letter to Hartsoeker, and stressed that it is not necessary for the introduction of a power-such as gravity - to specify anything other than the law it obeys; no extra requirements should be imposed, and in particular no requirement for a mechanical grounding. He said:

And therefore if any man should say that bodies attract one another by a power whose cause is unknown to us, or by a power seated in the frame of nature by the will of God, or by a power seated in a substance in which bodies move and float without resistance and which has therefore no vis inertiae but acts by other laws than those that are mechanical: I know not why he should be said to introduce miracles and occult qualities and fictions into the world $(2004,116)$.

There is hardly any need to relate here Newton's three laws of motion. ${ }^{16}$ What's important to note is that for Newton these laws were not metaphysically necessary. As Cotes put it:

It is the province of true philosophy to derive the natures of things from causes that truly exist, and to seek those laws by which the supreme artificer willed to establish this most beautiful order of the world, not those laws by which he could have, had it so pleased him $(2004,52)$

There is little doubt that laws required a law-maker and this was God. But, for Newton, significantly and unlike Descartes, God could have established different laws. Hence, the laws are metaphysically contingent; they could be different from what they are. The task then of natural philosophy is to discover the actual laws of nature-the ones God did establish. The key point here is that since God could have established other laws, finding the actual laws cannot a matter of a priori theorising (as Descartes suggested) but of a broadly empirical investigation. Indeed, Cotes says:

From this source [God's perfectly free will], then, have all the laws that are called laws of nature come, in which many traces of the highest wisdom and counsel certainly appear, but no traces of necessity. Accordingly we should not seek these laws by using untrustworthy conjectures, but learn them by observing and experimenting $(2004,57)$.

How can it be that there are no traces of necessity in the laws of nature? If laws were metaphysically necessary there would be known a priori; hence independently of experience. But for Newton and Cotes there cannot be a priori knowledge of laws of nature, since the laws are free choices of God. And if laws where metaphysically necessary they would not the free choice of God. Hence there is a dilemma: either the claim is that laws hold with metaphysical necessity, but then this would not make the laws the free choice of the author of the universe; or the claim is that God was free in the choice of laws, but then they cannot be known a priori. The first horn is taken by Descartes; the second by Newton. Cotes puts the point thus:

He who is confident that he can truly find the principles of physics, and the laws of things,

${ }^{16}$ For some insightful points concerning mathematical and physical characterisations of forces by Newton, see Janiak (2007). The relevant literature is, of course, vast. 
by relying only on the force of his mind and the internal light of his reason should maintain either that the world has existed from necessity and follows the said laws from the same necessity, or that although the order of nature was constituted by the will of God, nevertheless a creature as small and insignificant as he is has a clear understanding of the way things should be $(2004,57)$.

Part of the point is that knowing the laws of nature a priori would be possible only on two conditions: either if there could be only one way the laws could be; and hence the laws were metaphysically necessary; or, should the laws be metaphysically contingent, if the human mind had the capacity to latch onto them independently of experience. Both conditions are denied by Newton. So to the question: 'What makes the laws laws, ultimately?' Newton's answer is: the will of God. Given that the laws are grounded directly in the will of God, they cannot but be in some sense necessary: once God wills them, they cannot but hold and govern the behaviour of things. Buy this is not metaphysical necessity but conditional or natural necessity. In this sense, for Newton there are naturally necessary connections in nature, expressed by the fundamental laws of nature, but the only way to find them out is empirically (and hence fallibly).

Newton then, unlike Hume, takes it to be the case that laws are not mere regularities; however, he takes it that they can be known only as (mathematically characterised) regularities. This leads to a drastic reconceptualisation of laws of nature as primarily mathematical principles which characterise the basic structure of the world and place constraints on the explanation and description of natural processes, but are known empirically and not a priori. In his unsent letter to Cotes, in March 1713, Newton noted:

\begin{abstract}
I like your design of adding something more particularly concerning the manner of philosophizing made use of in the Principia and wherein it differs from the method of others, viz. by deducing things mathematically from principles derived from phenomena by induction. These principles are the three laws of motion. And these laws in being deduced from phenomena by induction and backed with reason and the three general rules of philosophizing are distinguished from hypotheses and considered as axioms. Upon these are founded all the propositions in the first and second book. And these propositions are in the third book applied to the motions of the heavenly bodies $(2004,109-110)$.
\end{abstract}

\title{
8. Concluding thoughts
}

During the seventeenth century, there is a clear shift from powers as regularity enforcers to laws as regularity-enforcers. Medieval powers yielded a bottom-up necessity: laws were metaphors for naturally necessary connections among powerful substances. But during the seventeenth century, laws replaced natural powers as principles of connection. Laws yield a top-down necessity. They derive their necessity from a law-giver and they determine how things must behave in the world; that is, they ground and explain the regular patterns there are in the world. Laws, in this sense, are 'behind' the regularity there is in the world and ground it.

As we have seen, however, laws kept a key feature of powers: they imposed necessary connections in nature, though there was a shift in how exactly necessity was conceived. Cartesian laws hold with metaphysical necessity; not so for the rest of the thinkers we examined: laws hold with natural necessity and impose patterns of naturally necessary connections in nature. 
The shift from powers to laws came with a tension, which was accentuated by the fact that matter was taken to be inert and causally inactive. This tension is captured by the following two questions: How can things obey laws if they do not have the power to do so? How can a powerless matter execute the laws?

Laws are supposed to govern the behaviour of things; things in some sense obey them and hence execute them. But as Leibniz forcefully argued, for matter to be capable of executing a law, matter must have suitable powers. With Leibniz powers re-enter the stage as that in virtue of which bodies are subject to laws and able to execute/obey the laws. Laws then seem to require powers to enforce necessary connections in the world. But how do objects acquire their powers? For Leibniz, as we have seen, powers are identified independently of laws.

But two other answers to this question became available. One was Hume's, and the other was Newton's. For Hume, there are no powers. The laws of nature are regularities. For Newton, powers and laws enter the world hand-in-hand, as it were. Unlike Hume, Newton was far from accepting that there is no natural necessity. Still, of this necessity nothing can be known except whatever is given to us as (mathematically characterised) regularities. If there is natural necessity in nature, (Newton thinks there is), it can never be found out.

But let's compare Newton with Hume once more: If God is left out of the picture, and if natural necessity cannot be otherwise grounded in (the independently posited) natures or powers all we are left with are regularities which can be known only as (mathematically characterised) regularities (and never qua natural necessities). These, plausibly, are the laws of nature for both Hume and Newton.

\section{Acknowledgement}

I would like to thank Lydia Patton and Walter Ott for their immense patience and encouragement. Walter's work has been a great source of inspiration and ideas. Many of the ideas expressed in this paper were extensively discussed with Robert DiSalle and Stavros Ioannidis, whom I thank wholeheartedly. Earlier versions of this paper were presented in an invited talk at the Rotman Institute of Philosophy-Engaging Science in June 1016; as part of a symposium (in absentia) in the HoPoS Conference in Minneapolis in June 2016; and in the inaugural Conference of the POND-Philosophy of Science around the Mediterranean in Jerusalem in September 2016. My thanks go to several members of the audiences for comments and questions.

\section{References}

Adams, Robert Merrihew. 2013. 'Malebranche's Causal Concepts'. In Eric Watkins (ed.) The Divine Order, the Human Order, and the Order of Nature, Oxford: Oxford University Press.

Ayers, Michael. 1996. 'Natures and Laws from Descartes to Hume'. In G. A. J. Rogers and Sylvana Tomaselli (eds) The Philosophical Canon in the Seventeenth and Eighteenth Centuries: Essays in Honour of John W. Yolton. University of Rochester Press.

Berkeley, George. 2008. Philosophical Writings. Cambridge Texts in the History of Philosophy. Desmond Clarke (ed.). Cambridge: Cambridge University Press.

Cohen, I. Bernard. 1964. 'Quantum in Se Est': Newton's Concept of Inertia in Relation to Descartes and Lucretius'. Notes and Records of the Royal Society 
of London 19: 131-155.

Descartes, R. 1982. Principles of Philosophy. Miller, V.R. and Miller, R.P. (trans)

Dordrecht: D. Reidel Publishing Company.

Descartes Rene. 1984. The Philosophical Writings of Descartes. J. Cottingham, R.

Stoothoff, and D. Murdoch (eds and trans). 2 vols. Cambridge: Cambridge

University Press.

Descartes Rene. 1991. The Philosophical Writings of Descartes. Volume 3: The

Correspondence by Rene Descartes; John Cottingham; Robert Soothoff;

Dugald Murdoch; Anthony Kenny (eds and trans). Cambridge: Cambridge

University Press.

Descartes, Rene. 1998. The World and Other Writings. Cambridge Texts in the History of Philosophy. Stephen Gaukroger (ed.). Cambridge: Cambridge University Press.

Garber, Daniel. 1992. Descartes' Metaphysical Physics. Chicago: University of Chicago Press.

Garber, Daniel. 2013. 'God, Laws, and the Order of Nature: Descartes and Leibniz, Hobbes and Spinoza'. In Eric Watkins (ed.), The Divine Order, the Human Order, and the Order of Nature. Oxford: Oxford University Press.

Garber, Daniel. 2016. 'Natural Philosophy in Seventeenth-Century Context', in Al. P. Martinich \& K. Hoekstra (eds), The Oxford Handbook of Hobbes, Oxford: Oxford University Press.

Goudarouli, Irene \& Psillos, Stathis. Forthcoming. 'Hobbes on Laws of Nature: From De Corpore to Leviathan and Back Again'

Henry, J. 2004. 'Metaphysics and the Origins of Modern Science: Descartes and the Importance of Laws of Nature'. Early Science and Medicine 9: 73-114.

Hume, David. 2007. An Enquiry concerning Human Understanding. Peter Millican (ed.). Oxford: Oxford University Press.

Janiak, Andrew. 2007. 'Newton and the Reality of Force'. Journal of the History of Philosophy 45: 127-147

Leibniz, G. W. 1989. Philosophical Papers and Letters. A Selection Translated and Edited, with an Introduction by Loemker. $2^{\text {nd }}$ edition. Dordrecht: Kluwer Academic Publishers.

Malebranche, Nicolas. 1923. Dialogues on Metaphysics and on Religion. Morris Ginsberg (trans). London: George Allen \& Unwin Ltd.

Malebranche, Nicolas. 1992. Treatise on Nature and Grace. Patrick Riley (trans). Oxford: Clarendon Press.

Malebranche, Nicolas. 1997. The Search after Truth. Cambridge Texts in the History of Philosophy. T. M. Lennon and P. J. Olscamp, Trans. Cambridge: Cambridge University Press.

McCord Adams, Marilyn. 2013. 'Powers versus Laws: God and the Order of the World According to Some Late Medieval Aristotelians'. In Eric Watkins (ed.), The Divine Order, the Human Order, and the Order of Nature, Oxford: Oxford University Press.

Nadler, Steven. 2011. Occasionalism: Causation among the Cartesians. Oxford: Oxford University Press.

Newton, Isaac. 2004. Philosophical Writings. Cambridge Texts in the History of Philosophy. Andrew Janiak (ed.), Cambridge: Cambridge University Press.

Ott, Walter. 2009. Causation and Laws of Nature in Early Modern Philosophy. Oxford: Clarendon Press. 
Pessin, Andrew. 2001. 'Malebranche's Distinction between General and Particular Volitions'. Journal of the History of Philosophy 39:77-99

Psillos, Stathis, 2002. Causation and Explanation. Acumen.

Smith, George. 2002. 'The Methodology of the Principia'. In I. Bernard Cohen and George Smith (eds) The Cambridge Companion to Newton. Cambridge: Cambridge University Press.

Suárez, Francisco. 1944. Selections from Three Works of Francisco Suárez, 2 volumes, translated by G. L. Williams, A. Brown \& J. Waldron, with revisions by H. Davis, Oxford: Clarendon Press; London: H. Milford.

Watkins, Eric ed. 2013. The Divine Order, the Human Order, and the Order of Nature, Oxford: Oxford University Press. 